\title{
Olímpica 9: louvação a Efarmosto e o mito do dilúvio Glória Braga Onelley
}

RESUMO

Píndaro (518-438 a.C.), poeta que se notabilizou como cultor de epinícios - cantos triunfais compostos, em geral, em honra dos vencedores das principais competições pan-helênicas -, celebrou na ode Olímpica 9, composta em 466 a.C., a vitória de Efarmosto de Opunte, na luta, por ocasião da $78^{a}$ Olimpíada realizada em 468 a.C. Nessa ode, privilegia-se o mito do dilúvio, cujos protagonistas são Deucalião e Pirra, ancestrais míticos dos Lócrios de Opunte, cidade do laureado. Esse epinício foi cantado durante o cortejo processional que se dirigiu ao santuário de Ájax, herói cultuado em Opunte.

PALAVRAS-CHAVE

Píndaro; epinícios; Olímpica 9; mito do dilúvio. 


\section{ЕФАРMO $\Sigma T \Omega I O \Pi O Y N T I \Omega I \Pi A \wedge A I \Sigma T H I$}

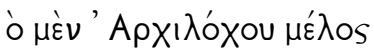

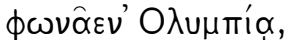

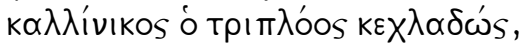

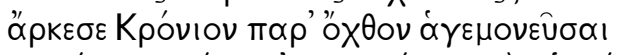

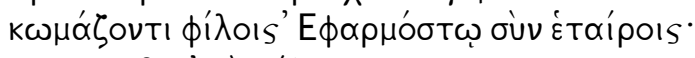

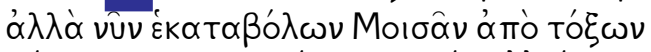

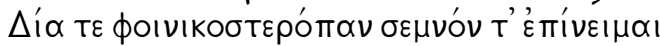

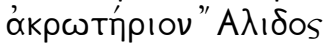

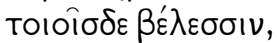

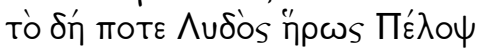

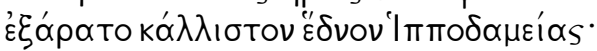

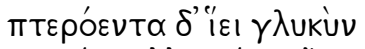

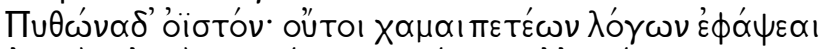

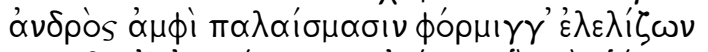

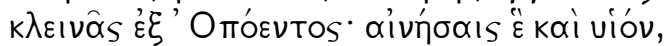

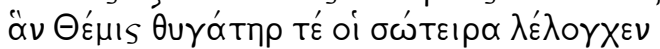

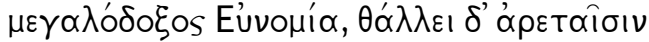

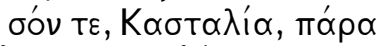

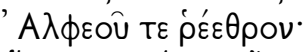

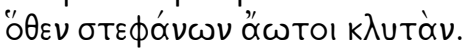

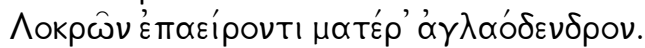

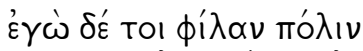

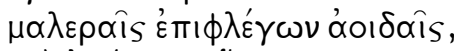

kai årávopos iा iाто

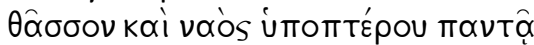

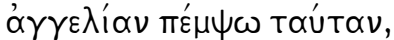

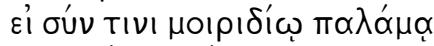

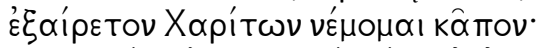

кEิ

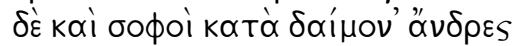

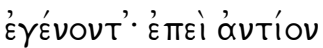

$\pi \omega \hat{s}$ âv tpı́óovtos 'H-

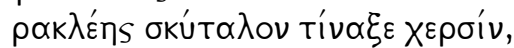

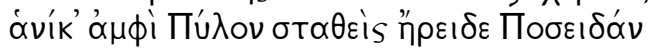

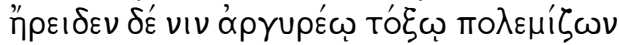

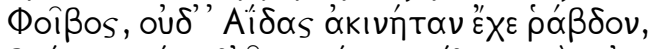

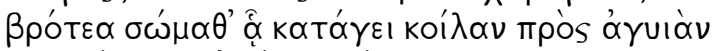

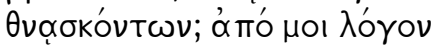

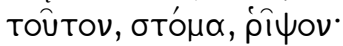

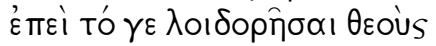

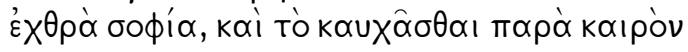




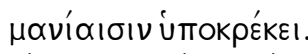

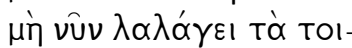

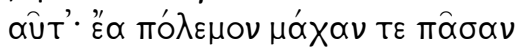

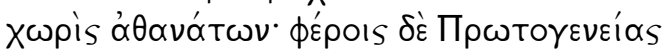

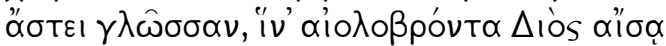

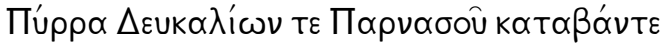

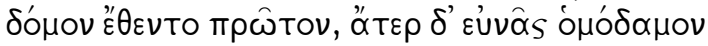

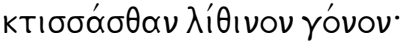

$\lambda \propto o i \delta^{\prime}$ ovú $\mu \alpha \sigma \theta \varepsilon v$.

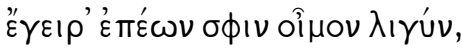

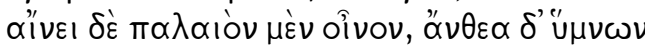

$v \varepsilon \omega T \varepsilon^{\prime} \rho \omega \nu . \lambda \varepsilon^{\prime} \gamma O \nu T I \mu \alpha \dot{\alpha} \nu$

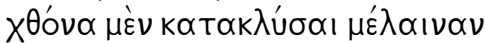

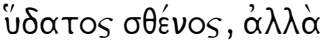

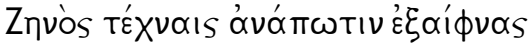

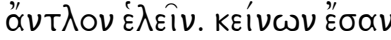

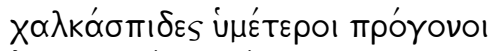

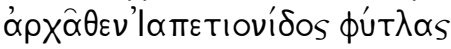

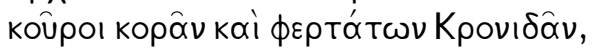

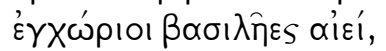

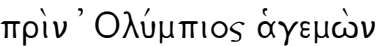

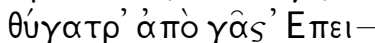

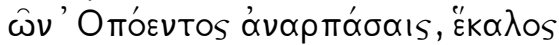

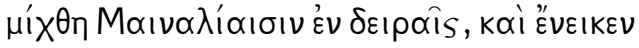

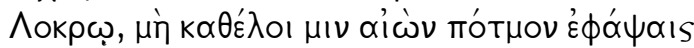

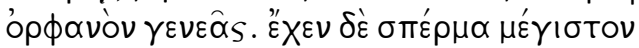

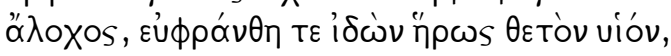

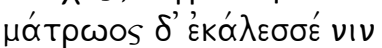

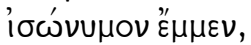

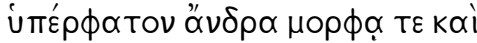

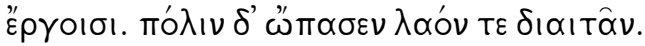

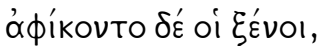

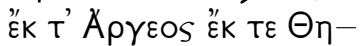

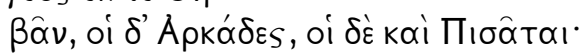

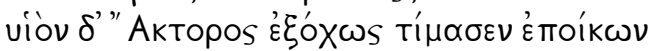

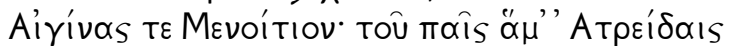

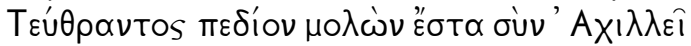

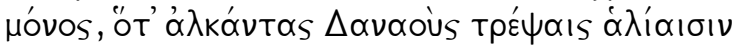

$\pi \rho \dot{\mu} \mu \nu \alpha$ Is Tí $\lambda \varepsilon \phi \circ$ š $^{\prime} \mu \beta \alpha \lambda \varepsilon v$.

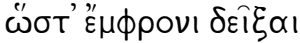

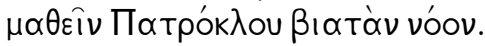




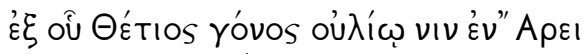

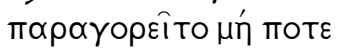

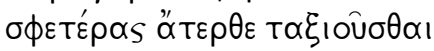

$\delta \propto \mu \alpha \sigma ı \mu \beta p o ́ t o v ~ \alpha i x \mu \alpha \hat{s}$.

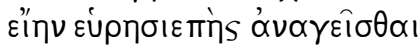

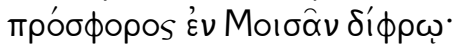

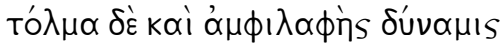

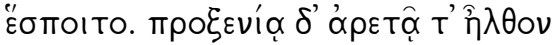

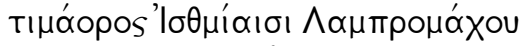

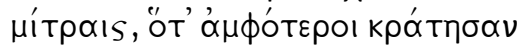

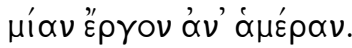

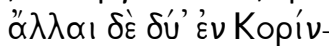

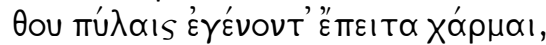

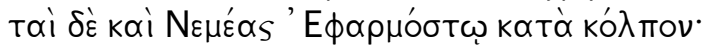

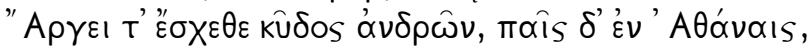

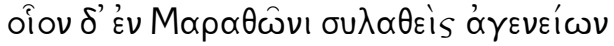

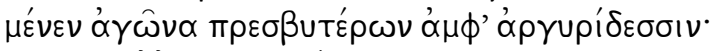

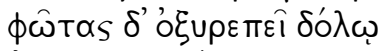

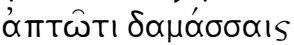

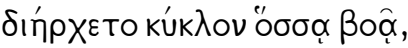

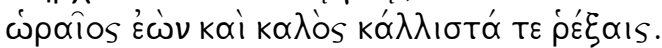

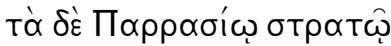

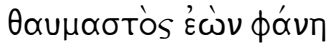

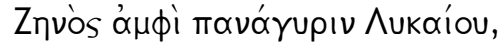

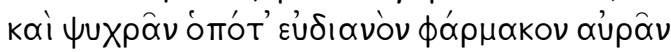

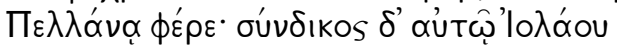

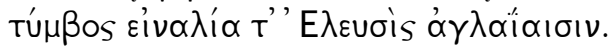

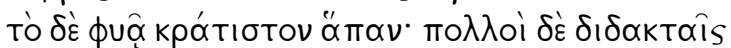

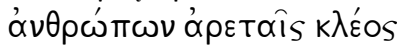

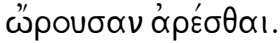

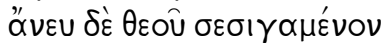

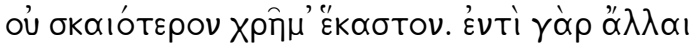

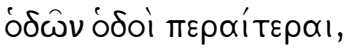

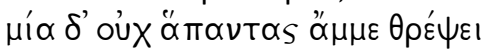

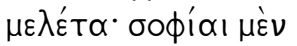

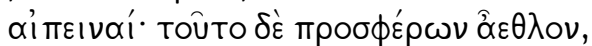

op

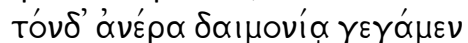

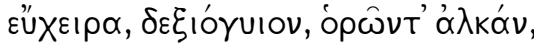

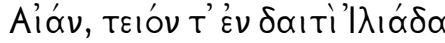

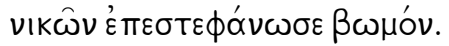


Olimpica 9*

A Efarmosto de Opunte, ${ }^{1}$ vencedor na luta em 466 a.C.

O canto de Arquíloco ${ }^{2}$

entoado em Olímpia,

este triplo canto de vitória,

bastou para conduzir, junto da colina de Cronos,

Efarmosto, que acompanhou o cortejo processional com seus

[queridos

companheiros.

Mas, agora, dos arcos das Musas que lançam seus dardos ao longe ${ }^{3}$

cobre, com essas setas,

Zeus de rubro raio

e o monte sagrado da Élide,

que outrora Pélops, o herói lídio,

conquistara com o belíssimo dote de Hipodamia;

e lança a doce alada

flecha em direção a Delfos; ${ }^{4}$ certamente, em palavras caídas por terra

[não tocarás,

fazendo vibrar a lira em honra das lutas de um homem

da famosa Opunte, louvando o seu filho ${ }^{5}$ e a ela, ${ }^{6}$

cidade que Têmis ${ }^{7}$ e sua filha salvadora, a

ilustre Eunomia, ${ }^{8}$ obtiveram por sorte. A cidade floresce por seus

[feitos

junto de tua corrente, ó Castália, ${ }^{9}$

e da corrente do Alfeu, ${ }^{10}$

de onde a fina flor das coroas

exaltam a célebre mãe ${ }^{11}$ dos Lócrios, de belas árvores.

E eu, inflamando a estimada cidade

com cantos ardentes, ${ }^{12}$

e mais rápido do que imponente cavalo

e do que nau alada, por toda a parte

enviarei esta mensagem,

se, com a ajuda de uma arte dada pelo destino,

cultivo o seleto jardim das Graças, ${ }^{13}$

pois os deleites elas concedem; bons 
e sábios, de acordo com a divindade ${ }^{14}$ tornam-se os homens; de fato, contra

o tridente, como teria

Héracles brandido nas mãos sua clava

quando Posêidon, tendo-se posicionado em defesa de Pilos,

pressionava,

e Febo o coagia firmemente lutando com seu arco de prata,

e nem Hades mantinha seu bastão imóvel,

com o qual faz descer para a sua oca morada os corpos

dos que morrem? Afasta de mim

esse discurso, ó boca! ${ }^{15}$

Porque o insultar os deuses

é uma arte odiosa, e o vangloriar-se inoportunamente

soa em harmonia com a loucura.

Agora, não balbucies tais

coisas! Deixa a guerra e toda a luta

longe dos imortais! Que conduzas tua língua

para a cidade de Protogenia, ${ }^{16}$ onde, por vontade de Zeus que lança

[o trovão,

Pirra e Deucalião, ${ }^{17}$ tendo descido do Parnaso,

fixaram primeiramente morada, e, sem partilharem o leito,

fundaram uma descendência de pedra, de uma raça unida;

e ela foi nomeada gente.

Desperta (tu) para eles ${ }^{18}$ uma via sonora de versos,

e louva o antigo vinho e as flores dos hinos

mais novos. ${ }^{19}$ Dizem, na verdade,

que a força das águas inundou

a terra negra, mas,

graças às habilidades de Zeus, repentinamente, a vazante

apoderou-se da inundação. Deles descendiam

vossos antepassados de escudos de bronze,

desde o início, filhos das filhas de raça de Jápeto

e dos incomparáveis filhos de Cronos, 
sempre reis da própria terra,

até que o soberano Olímpio,

tendo raptado da terra dos Epeios ${ }^{20}$ a filha

de Opunte, tranquilamente

a ela se uniu nos desfiladeiros de Ménalo, ${ }^{21}$ e trouxe-a

para Locro, para que o tempo não o destruísse, fixando-lhe um destino

isento de filhos. Mas sua esposa carregava o

poderosíssimo sêmen, e o herói deleitou-se ao ver o filho adotivo;

e disse que o nome dele

era o mesmo do pai de sua mãe,

um incrível varão em beleza e

façanhas. Deu-lhe para governar a cidade e o povo.

E chegaram junto dele estrangeiros

de Argos e de Tebas,

uns eram Árcades, outros, de Pisa.

Mas entre os colonos honrou sobretudo o filho de Áctor

e de Egina, Menécio. ${ }^{22} \mathrm{O}$ filho dele, ${ }^{23}$ tendo ido

com os Atridas para a planície de Teutrante, resistiu, sozinho,

[com Aquiles

quando Télefo, tendo posto em fuga os valentes Dânaos,

se lançou sobre as proas marinhas,

de sorte que se mostrou ao prudente

conhecer o espírito poderoso de Pátroclo.

Desde então, o filho de Tétis

exortou-o a nunca, em fatal Combate, ${ }^{24}$

se posicionar longe de sua

lança dominadora de homens.

Que eu seja fluente em versos para avançar

convenientemente no carro das Musas!

Ousadia e vasto poder

me sigam! Por causa da hospitalidade e da excelência, vim 
para honrar as faixas ístmicas de Lamprômaco ${ }^{25}$

quando ambos alcançaram

uma vitória num único dia.

Duas outras alegrias, ${ }^{26}$ nas portas

de Corinto, ocorreram depois,

e outras ainda para Efarmosto no vale de Nemeia.

Em Argos, obteve glória entre os homens, e, ainda rapaz, em Atenas.

Que disputa, em Maratona, separado dos imberbes,

ele aguentou entre os mais velhos pelas taças de prata!

Com equilibrada e invencível astúcia,

tendo subjugado homens adultos,

com que grito atravessou o círculo de espectadores

sendo jovem e belo e tendo realizado belíssimos feitos!

Por outro lado, para o povo parrásio ${ }^{27}$

apareceu digno de admiração

no festival de Zeus Lício,

quando o quente amuleto dos gélidos ventos

ele obteve em Pelene. ${ }^{28}$ Testemunhas de seus triunfos

são o túmulo de Iolau $^{29}$ e a marinha Elêusis. ${ }^{30}$

Por natureza, tudo é melhor; entre os homens, muitos,

com proezas aprendidas,

se esforçam por alcançar a glória.

Mas, sem a divindade, cada coisa guardada em silêncio

não é pior; na verdade, há outros

caminhos mais longos do que outros,

e um único assunto não instruirá

a todos nós; as artes são

difíceis de atingir; ao ofereceres esse prêmio,

grita em alta voz com audácia:

este homem, graças à divindade, nasceu

com mão habilidosa, agilidade nos membros e olhar firme.

E na tua festa, ó Ájax, ${ }^{31}$ filho de Ileu, 
ele, ao vencer, depositou a coroa em teu altar.

\section{ABSTRACT}

Olympian 9: Laudation to Epharmostus and the Flood Myth

Pindar (518-438 BC), a poet who was notable as an author of epinicians - triumphal chants that were composed, generally, for honor of the winners of the main panhellenic competitions, had celebrated in the Olympian 9 ode, composed in $466 \mathrm{BC}$, the victory of Epharmostus of Opus, in the wrestling-match, on the occasion of the $78^{\text {th }}$ Olympiad that took place in 468 BC. In that ode, it is emphasized the flood myth, whose protagonists are Deucalion and Pyrrha, mythical ancestors of the Locrians of Opus, city of the laureate. That epinician was chanted during the procession that headed to the sanctuary of Ajax, a hero who was adored in Opus.

KEYWORDS 
Pindar; epinicians; Olympian 9; flood myth.

NOTAS

*A tradução de Olimpica 9, elaborada especialmente com base no Lexicon to Pindar editado por William Slater, constitui parte da pesquisa interinstitucional (UFRJ/UFF) por mim desenvolvida em parceria com a professora Dra Shirley Fatima G. de Almeida Peçanha. A edição crítica da tradução é a estabelecida por Snell-Maehler 1987.

${ }^{1}$ A Olimpica 9 celebra a vitória de Efarmosto de Opunte - cidade da Lócrida situada em frente ao golfo de Corinto -, nos Jogos Olímpicos de 468 a.C., como atestam os escoliastas e o papiro 222 da coleção de Oxirrinco (apud: Jesus. O canto do dilúvio: Olímpica Ix. In: JEsus, 2006, p. 70), muito embora tenha sido a ode executada em 466 a.C. O herói cultuado em Opunte era Ájax da Lócrida (v. 112), filho de Ileu, também denominado Oileu.

${ }^{2}$ Antigo canto de vitória em honra de Héracles, possivelmente uma espécie de refrão atribuído ao poeta Arquíloco de Paros (séc. VII a.C.), com o qual se acompanhava o laureado até o altar de Zeus quando não se tinha uma ode para celebrar o vencedor. Esse refrão, constituído de três versos, recebeu na edição de West o número 324 que, segundo o helenista inglês, é de autoria incerta: viva o feliz vencedor," salve o soberano Héracles" tu e Iolau, um par de guerreiros (apud: JEsus. O canto do dilúvio: Olímpica IX. In: JESUS, 2006, p. 70).

${ }^{3}$ Os dardos das Musas simbolizam os versos pindáricos, cujo alvo é o vencedor olímpico. Essa imagem está presente no v. 11 dessa mesma ode e também em Olimpica 2 (89-90: "Agora, aponta o arco para o alvo: vai, meu coração! Quem devemos atingir/ de novo, lançando de nosso delicado ânimo as gloriosas flechas?" Tradução nossa.).

${ }^{4}$ Referência à vitória de Efarmosto nos Jogos Píticos (Píndaro. Odas y Fragmentos, 1984, p.114).

${ }^{5} \mathrm{O}$ filho da cidade de Opunte é Efarmosto, o atleta vencedor.

${ }^{6}$ Referência à cidade de Opunte.

${ }^{7}$ Têmis, filha de Urano e Geia, é a deusa da lei.

${ }^{8}$ Eunomia é uma das Horas, filha de Têmis (HEsíodo, Teogonia, v. 902). Em Olimpica 9, personifica a Ordem.

${ }^{9}$ Castália, uma fonte dedicada a Apolo e situada no Parnaso.

${ }^{10}$ Alfeu, rio perto de Olímpia, que fica situada na região da Élide na península do Peloponeso.

${ }^{11}$ Referência à cidade de Opunte.

${ }^{12}$ Metáfora da palavra poética.

${ }^{13}$ As Graças são três divindades, Aglaé, Eufrosina e Talia, cujas atribuições estão vinculadas às atividades intelectuais, aos deleites da vida e à beleza. Em outras odes de Píndaro, figuram essas divindades também, ao lado das Musas e de Apolo, como inspiradoras da composição poética (e.g. Nemeia, 9, v. 54-5; Olimpica 14). Em Olimpica 14 , apresenta-se uma prece às Graças, invocadas como inspiradoras da voz do poema, na perfeita elaboração de seus versos, e do atleta homenageado, Asópico de Orcômeno, vencedor na corrida de estádio provavelmente em 488 a.C.

${ }^{14}$ A expressão adverbial katà daimon, "de acordo com a divindade", alude à concepção 
pindárica de que os feitos dos homens não dependem exclusivamente de suas habilidades, mas necessitam da benevolência divina, como reiteram os v. 100-4. Essa concepção é também válida para os semideuses, como evidenciam os versos 29b-35a, nos quais Héracles, na expedição contra Pilos, segundo a versão presente na ode em pauta, lutara contra o rei Neleu que, embora tivesse tido como aliados Posêidon, Apolo e Hades, foi vencido pelo herói. Com efeito, do questionamento inserto nos referidos versos, transparece o auxílio divino a Héracles. Acerca desse episódio, salienta Puech (1970, p. 117, nota 6), a julgar pelos escólios à ode em tela, Píndaro teria criado uma nova versão mítica sobre as aventuras de Héracles, ao reunir numa só narrativa três combates distintos, a saber, a luta de Héracles contra Posêidon quando o herói se dirigia a Pilos para solicitar do rei Neleu a purificação por conta de um assassinato; a luta contra Apolo após o roubo do tripé profético e a luta contra Hades, por ocasião do rapto de Cérbero ( $11^{\circ}$ trabalho de Héracles ).

${ }^{15}$ Os versos compreendidos entre 35b e 41a evidenciam a concepção religiosa presente em Píndaro, segundo a qual não se deve macular a imagem dos deuses. Essa reflexão dialoga com os versos 35-6 e 52-3 de Olímpica 1, respectivamente: "Fica bem ao homem dizer/ coisas belas a respeito dos deuses: menor será a culpa"; "A mim é impossível chamar de antropófago/ qualquer um dos bem-aventurados. Recusome!”'Tradução nossa.).

${ }^{16}$ A cidade de Protogenia é Opunte, que é não só o nome do monarca lendário, mas também o nome da cidade do vencedor. De acordo com a versão tradicional do mito, Protogenia é a primeira filha de Deucalião e Pirra nascida após a inundação, daí o sentido de Primogênita. Essa filiação é sugerida, ao que parece, nos versos pindáricos (v. 42-3) pela contiguidade desses três nomes. A julgar pelos escólios à Olimpica 9 (apud: Grimal, 1997, p. 399, nota "Protogenia 1"), Protogenia era filha de Opunte, rei da Élide, que, tendo sido raptada por Zeus, dele teve um filho, o qual recebeu o mesmo nome do avô, isto é, Opunte. Foi esse filho de Protogenia criado pelo pai adotivo Locro, rei da Lócrida. São esses os comentários dos escólios aos v. 57-66 da Olímpica 9 , versos que correspondem às linhas 84 segg. comentadas pelos escoliastas, como citou Grimal. Cabe ressaltar que, segundo a versão mítica tradicional (GRIMAL, 1997, p. 285, verbete "Locro"), a jovem que se uniu a Zeus no monte Mênalo não foi Protogenia, mas sim a filha de Opunte, rei da Élide, de nome Cabia, não mencionado nos v. 57-66 da ode.

${ }^{17}$ Segundo a versão mítica tradicional, Deucalião, filho de Prometeu e Clímene, e sua esposa Pirra, filha de Epimeteu e Pandora, foram os únicos sobreviventes do dilúvio (v. 49b-53a) enviado por Zeus como castigo aos homens da Idade do Bronze em razão de terem eles comportamento corrupto e vicioso. Após nove dias e nove noites de dilúvio, aportaram no Parnaso, e, segundo a versão pindárica, estabeleceram sua primeira morada em Opunte (v. 43), dado não referido na narrativa tradicional. Em virtude de Deucalião mostrar-se desejoso de ter companheiros, Zeus ordenou-lhe e também a Pirra que atirassem para trás dos ombros os ossos de suas respectivas mães. Pirra ficou aterrorizada com esse pedido, mas Deucalião compreendeu que os ossos maternos eram as pedras, isto é, os ossos da Terra, a Mãe universal. Assim, das pedras arremessadas por Pirra nasceram mulheres e das lançadas por Deucalião, homens. Essa geração pétrea e assexuada é referida na ode em tela, respectivamente, 
pelos sintagmas líthinon gónon (v. 45), “ descendência de pedra”, e áter' eunâs (v. 44), "sem o leito", traduzido por "sem partilharem o leito".

${ }^{18} \mathrm{O}$ pronome sphin, segundo Puech (PINDARE, 1970, p.118. Nota 5), refere-se aos primeiros Lócrios e não somente a seus ancestrais míticos Deucalião e Pirra.

${ }^{19}$ A antítese presente nas expressões palaiòn mèn oînon (v. 48), "antigo vinho", e ánthea d' býmnon neôtérôn (v. 48-9), " flores dos hinos mais novos", alude ao dilúvio e ao louvor do poeta aos Lócrios, respectivamente (In: PíNDARO, 1984, p. 115-6. Em nota de rodapé).

${ }^{20}$ Epeios é o antigo nome dos habitantes da Élide, cujo rei era Opunte. Sua filha, não nomeada na ode (v. 58), foi raptada por Zeus e dele teve um filho, que recebeu o mesmo nome do avô, isto é, Opunte, e foi criado por Locro, rei da Lócrida. Ver também nota 16 .

${ }^{21}$ Mênalo, monte ao sul da Arcádia.

${ }^{22}$ Menécio, pai de Pátroclo, foi um estrangeiro que fixou morada em Opunte.

${ }^{23}$ Referência ao herói Pátroclo, que, antes de chegar a Troia com os demais Dânaos, aporta na Mísia, onde, junto com Aquiles, enfrenta Télefo, filho adotivo de Teutra, rei da Mísia (v. 70-9). Esse mito é relativo ao Ciclo Épico.

${ }^{24}$ Slater traduz a expressão oulíoi... en Árei (v. 76) por "em fatal Combate". Note-se que Ares, deus da guerra, representa o espírito belicoso que se deleita com a carnificina e com o sangue, donde a tradução de Árei por "Combate" com inicial maiúscula.

${ }^{25}$ Lamprômaco era parente de Efarmosto, e, segundo Ortega (In: PínDARO, 1984, p. 117. Nota 82) e Puech (In: PINDARE, 1970, p. 114), encomendara a Píndaro esta ode triunfal.

${ }^{26}$ Referência às vitórias de Efarmosto em outras competições atléticas (v. 85-99).

${ }^{27}$ Habitante de Parrásia, pequena região da Arcádia em volta do monte Lício, onde havia um templo dedicado a Zeus.

${ }^{28}$ Pelene, cidade da Acaia, na qual se realizavam jogos em honra de Apolo cujo prêmio era uma capa de lã, metaforicamente indicada, na ode em pauta, pelo sintagma eudianòn phármakon (v. 97), "quente amuleto" (In: PíNDARO, 1984, p. 118).

${ }^{29}$ Iolau é sobrinho de Héracles e filho de Íficles, meio-irmão do herói. Como informa Puech (PINDAre, 1970, p. 121. Nota 1), junto do túmulo de Iolau, realizavam-se os jogos tebanos.

${ }^{30}$ Referência aos jogos realizados em Elêusis em honra de Deméter, também chamados Demétria, anota, ainda, Puech (ibidem). Em Olimpica 13, v. 110, alude-se a essas competições.

${ }^{31}$ Ájax, filho de Ileu ou Oileu, combateu em Troia como chefe do contingente da Lócrida, tendo lutado também ao lado do rei de Salamina, Ájax, filho de Têlamon. Uma distinção entre esses dois heróis encontra-se em Ilíada, II, v. 527-35.

\section{REFERÊNCIAS BIBLIOGRÁFICAS}

GRIMAL, Pierre. Dicionário de mitologia grega e romana. 3. ed. Tradução de Victor Jabouille. Rio de Janeiro: Bertrand Brasil, 1997.

Hervicus, Maehler; snell, Bruno. Pindari carmina cum fragmentis. Pars I: Epinicia. Leipzig: Teubner, 1987. 
HESíODO. Teogonia; Trabalhos e Dias. Introdução, tradução e notas de Ana Elias Pinheiro e José Ribeiro Ferreira. Lisboa: Imprensa Nacional-Casa da Moeda, 2005. Homero. Ilíada. Tradução de Frederico Lourenço. Lisboa: Edições Cotovia, 2005. Jesus, Carlos A. Martins de. O canto do Dilúvio: Olímpica IX. In: LOUREnço, Frederico (Org.), Ensaios sobre Píndaro. Lisboa: Edições Cotovia, 2006.

PINDARE. Olympiques. Texte établi et traduit par Aimé Puech. $6^{\text {ème }}$. tirage. Paris: Les Belles Lettres, 1970.

PíNDARO. Odas y fragmentos: Olímpicas, Píticas, Nemeas, Ístmicas, Fragmentos. Madrid: Editorial Gredos, 1984.

Slater, William J. (ed.) Lexicon to Pindar. Berlin: Walter de Gruyter \& Co, 1969. 